Graduate Institute of

International and Development Studies Working Paper

No: 02/2011

\title{
Regulating Asset Price Risk
}

\author{
Philippe Bacchetta \\ University of Lausanne / CEPR \\ Cédric Tille \\ Graduate Institute of International Studies / CEPR \\ Eric van Wincoop \\ University of Virginia / NBER
}

\begin{abstract}
There has been a long debate about whether speculators are stabilizing or not. We consider a model where speculators have a stabilizing role in normal times, but may also provoke large risk panics. The very feature that makes arbitrageurs liquidity providers in normal times, namely their tolerance of risk, enables a large increase in asset price risk during a financial panic. We show that a policy that discourages balance sheet risk reduces the magnitude of financial panics, as well as asset price risk in both normal and panic states.
\end{abstract}

Keywords: Asset Pricing, Risk Management, Leverage.

JEL codes: E44, G11, G18

(C) The Authors.

All rights reserved. No part of this paper may be reproduced without the permission of the authors. 


\title{
Regulating Asset Price Risk ${ }^{1}$
}

\author{
Philippe Bacchetta \\ University of Lausanne \\ CEPR
}

\author{
Cédric Tille \\ Graduate Institute, Geneva \\ CEPR
}

\author{
Eric van Wincoop \\ University of Virginia \\ NBER
}

First draft November 2010, current draft: January 2011

\footnotetext{
${ }^{1}$ Prepared for the May 2011 issue of the American Economic Review, Papers and Proceedings. Session "New Approaches for Modeling Risk in Macroeconomics," session chair Hélène Rey. We thank Tarek Hassan for valable comments. Financial support by the National Centre of Competence in Research "Financial Valuation and Risk Management" (NCCR FINRISK) is gratefully acknowledged.
} 


\begin{abstract}
There has been a long debate about whether speculators are stabilizing or not. We consider a model where speculators have a stabilizing role in normal times, but may also provoke large risk panics. The very feature that makes arbitrageurs liquidity providers in normal times, namely their tolerance of risk, enables a large increase in asset price risk during a financial panic. We show that a policy that discourages balance sheet risk reduces the magnitude of financial panics, as well as asset price risk in both normal and panic states.
\end{abstract}

Keywords: Asset Pricing, Risk Management, Leverage.

JEL codes: E44, G11, G18 
So-called arbitrageurs or speculative investors, such as hedge funds and investment banks, play an important role in financial markets. By responding aggressively to expected return opportunities they provide liquidity in markets. Despite this role there have been regular calls for regulation of these investors. The traditional argument is that their aggressive behavior may be destabilizing when combined with imperfect information, expectational errors or herding. In the wake of the 2007-8 global financial crisis, the argument for regulation has emphasized systemic risk as these institutions are closely interconnected (e.g. Stephen Morris and Hyun Song Shin, 2008).

In this paper we develop a different argument for regulation, which is also connected to financial crises. Our focus is on asset price risk. The very feature that makes arbitrageurs liquidity providers in normal times, namely their tolerance of risk, enables a large increase in asset price risk during a financial panic (or even in normal times if investors take the probability of a future panic into account). We show that a policy that discourages balance sheet risk, the product of asset price risk and leverage, reduces the magnitude of financial panics, as well as asset price risk in both normal and panic states.

We reach this conclusion in the context of a model of "risk panics" that we previously developed in Philippe Bacchetta, Cédric Tille and Eric van Wincoop (2010), from hereon BTW. The model generates large self-fulfilling shifts in asset price risk, consistent with sharp surges in risk that have characterized recent financial crises. The VIX index quadrupled during the panic in the Fall of 2008 and tripled during the Greek debt crisis in the Spring of 2010.

The remainder of the paper is organized as follows. In section I we briefly describe the model of BTW. In section II we argue that equilibrium asset price risk can be reduced by a policy that punishes overall balance sheet risk (risk about net worth). It has the effect of making investors, or financial institutions, more risk-averse. Section III concludes.

\section{A Brief Description of the Model}

There are overlapping generations of two types of agents, households and investors. We can think of investors as leveraged financial institutions. They are born with an endowment that they invest in stocks and bonds. They are leveraged when 
their bond holding is negative. Households invest their endowment in bonds and a riskfree household technology.

There is a stochastic i.i.d. dividend and, more importantly, persistent wealth shocks. These relate to the initial endowments of investors. BTW consider shocks that redistribute wealth between households and investors, but show that results are similar when only investors are hit by wealth shocks. In terms of the 2007-2008 crisis we can relate these wealth shocks to losses associated with mortgage-backed securities or other derivatives.

Leverage is denoted by $\alpha_{t}$ and is equal to the fraction of wealth that investors allocate to stocks. We adopt simple mean-variance preferences, whereby investors maximize

$$
E_{t} R_{t+1}^{p}-0.5 \gamma \operatorname{var}_{t}\left(R_{t+1}^{p}\right)
$$

and the portfolio return is $R_{t+1}^{p}=\alpha_{t} R_{K, t+1}+\left(1-\alpha_{t}\right) R_{t}$. Here $R_{t}$ is the gross interest rate on bonds, which is determined in equilibrium. The equity return is $R_{K, t+1}=\left(Q_{t+1}+A_{t+1}\right) / Q_{t}$, where $Q_{t}$ is the equity price and $A_{t+1}$ is the dividend.

This generates the standard mean-variance portfolio

$$
\alpha_{t}=\frac{E_{t} R_{K, t+1}-R_{t}}{\operatorname{\gamma ar}_{t}\left(R_{K, t+1}\right)}
$$

This portfolio share is equal to the ratio of equity holdings relative to net worth, which is financial leverage. The model is closed by equilibrium in the stock and bond markets. The aggregate bond supply is zero. Equity market equilibrium implies that $\alpha_{t} W_{I, t}=Q_{t} K$, where $W_{I, t}$ is the initial endowment of investors and $K$ is the equity supply.

Using (2), equity market equilibrium becomes:

$$
Q_{t}=\frac{1}{R_{t}} E_{t} A_{t+1}+\frac{1}{R_{t}} E_{t} Q_{t+1}-\frac{\gamma K}{R_{t} W_{I, t}} \operatorname{var}_{t}\left(Q_{t+1}\right)
$$

The dynamic equation (3) implies that $Q_{t}$ depends on $\operatorname{var}_{t}\left(Q_{t+1}\right)$. Even when we rule out explosive rational bubbles, which can typically occur in forward-looking difference equations, there are multiple solutions to (3). If $\operatorname{var}_{t}\left(Q_{t+1}\right)$ is time varying it increases the variability of $Q_{t}$. Therefore, changes in perceived volatility create volatility, which leads to multiplicity.

The only state variable in the model is $\theta_{t}$, which affects the initial wealth $W_{I, t}$ of investors: $W_{I, t}=\left(1-\theta_{t}\right) \bar{W}_{I}$ in the quadratic approximation. $\theta_{t}$ follows an 
autoregressive process. BTW show that there are three types of equilibria. One is a regular fundamental equilibrium, where the equity price $Q_{t}$ depends on $\theta_{t}$ only to the extent that $\theta_{t}$ impacts the wealth $W_{I, t}$. The second type is a sunspot-like equilibrium, where $\theta_{t}$ has the dual role of a fundamental that affects the asset price through wealth and as a coordination device for time-varying beliefs about risk. This second role is entirely separate from its fundamental role. It even holds when $\theta_{t}$ is a pure sunspot that has no impact on wealth.

The sunspot-like equilibrium reflects a degree of freedom in the model with respect to beliefs about risk. It is driven by the negative link between the current asset price and risk about the future asset price in (3), which implies that risk about the future asset price depends on uncertainty about future risk. This dynamic mapping of risk into itself gives rise to the possibility of multiple equilibria related to different beliefs about the process of risk.

Finally, there are switching equilibria in which there are switches, driven by a Markov-process, between a low risk state (akin to the fundamental equilibrium) and a high risk state (akin to a sunspot-like equilibrium). A risk panic involves a switch to the high risk state. The panic is larger when the endowment of investors, around which risk beliefs are coordinated in the sunspot-like equilibrium, is low. During the panic the fundamental plays the role of a coordination device for a sudden large increase in beliefs about risk.

For a particular parameterization where investors are substantially leveraged (steady state leverage of about 4), BTW show that a risk panic implies a sharp spike in risk (quadruples, as during the 2008 panic) and a sharp drop in the equity price, market liquidity and financial leverage. The drop in leverage follows as investors reduce their exposure to equity as a result of increased risk. This smaller exposure in turn reduces market liquidity.

\section{Regulating Asset Price Risk}

While not explicit in the model, it is reasonable to assume that large asset price volatility is undesirable as a result of its impact on the real economy. We therefore ask what the government can do to limit equilibrium asset price risk. In particular, we consider policy that discourages balance sheet risk, which is the same as risk about future net worth and therefore risk about $R_{t+1}^{p}$. Specifically, assume that 
the government imposes a tax $\tau$ on this risk, so that for every unit of initial wealth the agents receive $R_{t+1}^{p}-\tau \cdot \operatorname{var}_{t}\left(R_{t+1}^{p}\right)$ rather than just $R_{t+1}^{p}$. They then maximize (1) minus $\tau \cdot \operatorname{var}_{t}\left(R_{t+1}^{p}\right)$. This has the impact of raising the effective risk aversion from $\gamma$ to $\gamma+2 \tau$. A tax on balance sheet risk therefore has the effect of making investors more risk averse.

We assess the impact of the tax by solving the model for different rates of risk aversion, using the parameterization of BTW. A lower rate of risk aversion reduces asset price volatility in the fundamental equilibrium. The coefficients $v$ and $V$ in the equilibrium $\log$-asset price $q_{t}=\tilde{q}-v \theta_{t}-V \theta_{t}^{2}$ both decrease. This is associated with the stabilizing role of leveraged investors as providers of liquidity. Market liquidity increases and risk declines as we make investors more aggressive by lowering their risk aversion. In this case the optimal policy involves a subsidy of balance sheet risk $(\tau<0)$, making investors more leveraged.

Next consider the sunspot-like equilibrium. Lower risk aversion significantly increases both $v$ and $V$ and raises asset price risk. Intuitively, lower risk aversion implies that agents are less responsive to changes in risk. It is exactly because investors are less responsive to risk that it is possible to have an equilibrium with large time-variation in risk, leading to high asset price volatility. In this case equilibrium asset price risk is reduced by taxing balance sheet risk $(\tau>0)$.

Finally consider the switching equilibrium discussed in BTW. In that case low risk aversion increases risk in both the low and high risk states. The high risk state becomes more volatile because of increased volatility in the sunspot-like equilibrium. The low risk state becomes more volatile because most of the risk in that state is connected to the possibility of a switch to the high risk state.

Table 1, which shows the equity price, risk, leverage, and liquidity in the switching equilibrium, illustrates these points. Risk is measured as the standard deviation of $Q_{t+1} / Q_{t}$, taking into account the possibility of switching to another state. Leverage is equal to the share of equity in investors' portfolio, $\alpha_{t}$. Finally, illiquidity is measured as the absolute value of the derivative of the log equity price with respect to $\theta_{t}$. The first column shows the value of these variables prior to any shock $\left(\theta_{t}\right.$ is at its unconditional mean and we are in the low risk state). The second column shows the variables when an increase in $\theta_{t}$ cuts the wealth $W_{I, t}$ of investors in half, while remaining in the low-risk state. We can think of this as the first year of the 2007-8 crisis before the fall of Lehman Brothers. The last column shows what 
happens when we switch to the high risk state, with the investors' endowment still being low. The top panel uses the parameterization in BTW, where risk aversion is $\gamma=1$. The bottom panel increases risk aversion to 5 .

Table 1 Role of Risk Aversion

\begin{tabular}{lccc}
\hline & peịsi\$o & starisi@f & hoight \\
\hline & \multicolumn{3}{c}{$\gamma=1$} \\
\hline equity price & 100 & 85 & 37 \\
risk & 5.0 & 15.0 & 56.3 \\
leverage & 4.5 & 8.2 & 3.6 \\
illiquidity & 0.28 & 0.83 & 4.5 \\
\hline \multicolumn{3}{c}{$\gamma=5$} \\
\hline equity price & 100 & 96 & 84 \\
risk & 1.1 & 2.8 & 7.0 \\
leverage & 4.8 & 10.1 & 8.9 \\
illiquidity & 0.07 & 0.19 & 0.73 \\
\hline
\end{tabular}

Higher risk aversion significantly reduces risk in all possible states. As a consequence, higher risk aversion significantly dampens the decline in the equity price in both the tranquil and panic stages of the crisis. Higher risk aversion also increases market liquidity, as seen in the last row of Table 1. This may seem counterintuitive as one might expect a less aggressive response to expected return changes to reduce market liquidity. But the reduced risk under higher risk aversion leads to increased leverage and therefore increased exposure to equity that improves market liquidity. We conclude that less aggressive investors end up generating less risk and a more liquid financial market. This provides a strong motivation for regulatory policy that limits balance sheet risk.

Interestingly, the problem is not leverage itself. Prior to the crisis, leverage is virtually the same for $\gamma=5$ as for $\gamma=1$, while it is substantially larger for $\gamma=5$ during the height of the crisis. A higher rate of risk aversion by itself would reduce leverage. But since it significantly reduces risk, it implies higher leverage in equilibrium. What matters is not leverage itself, but overall balance sheet risk $\operatorname{var}_{t}\left(R_{t+1}^{p}\right)$, which is the product of "leverage" and "risk" in Table 1. Even though the higher risk aversion leads to higher leverage, it reduces asset price risk by enough to actually lower balance sheet risk. 


\section{Conclusion}

There has been a long debate about whether speculators are stabilizing or not. We consider a model where speculators have a stabilizing role in normal times, but may also provoke large risk panics. The possibility of self-fulfilling shifts in beliefs about risk, consistent with large spikes in risk during recent financial crises, points to the desirability of a policy limiting balance sheet risk, though not necessarily leverage. This reduces the equilibrium level of asset price risk in both normal and panic states and improves market liquidity.

\section{References}

[1] Bacchetta, Philippe, Cédric Tille, and Eric van Wincoop (2010), "Self-fulfilling Risk Panics," NBER Working Paper No. 16159.

[2] Morris, Stephen and Hyun Song Shin (2008), "Financial Regulation in a System Context," Brookings Papers on Economic Activity, Fall 2008, 229-274. 